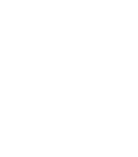
ANNUAL Further
REVIEWS

Click here for quick links to Annual Reviews content online, including:

- Other articles in this volume

- Top cited articles

- Top downloaded articles

- Our comprehensive search

Annu. Rev. Resour. Econ. 2014. 6:191-215

First published online as a Review in Advance on June 25, 2014

The Annual Review of Resource Economics is online at resource.annualreviews.org

This article's doi:

10.1146/annurev-resource-100913-012655

Copyright ( 2014 by Annual Reviews. All rights reserved

JEL codes: D04, F53, Q52, Q54, Q58

\section{Carbon Markets: Past, Present, and Future}

\section{Richard G. Newell, ${ }^{1,2,3}$ William A. Pizer, ${ }^{3,4,5,6}$ and Daniel Raimi ${ }^{2}$}

${ }^{1}$ Nicholas School of the Environment, Duke University, Durham, North Carolina 27708; email: richard.newell@duke.edu

${ }^{2}$ Duke University Energy Initiative, Duke University, Durham, North Carolina 27708; email: daniel.raimi@duke.edu

${ }^{3}$ National Bureau of Economic Research, Cambridge, Massachusetts 02138

${ }^{4}$ Sanford School of Public Policy and Nicholas Institute for Environmental Policy Solutions, Duke University, Durham, North Carolina 27708; email: william.pizer@duke.edu

${ }^{5}$ Resources for the Future, Washington, DC 20036

${ }^{6}$ Center for Global Development, Washington, DC 20036

\section{Keywords}

carbon market, tradable permit, allowance, climate change, greenhouse gas
Abstract
Carbon markets are substantial and expanding. There are many les- sons from experience over the past 9 years: fewer free allowances, careful moderation of low and high prices, and a recognition that trading systems require adjustments that have consequences for mar- ket participants and market confidence. Moreover, the emerging in- ternational architecture features separate emissions trading systems serving distinct jurisdictions. These programs are complemented by a variety of other types of policies alongside the carbon markets. This architecture sits in sharp contrast to the integrated global trading ar- chitecture envisioned 15 years ago by the designers of the Kyoto Pro- tocol and raises a suite of new questions. In this new architecture, jurisdictions with emissions trading have to decide how, whether, and when to link with one another, and policy makers must confront how to measure both the comparability of efforts among markets and the comparability between markets and a variety of other policy approaches. 


\section{WHY CARBON MARKETS?}

The 1980s and 1990s witnessed a growing awareness of climate change risks and the associated need to reduce greenhouse gas (GHG) emissions. Beginning with the first World Climate Conference in 1979, attention culminated with the signing of the UN Framework Convention on Climate Change (UNFCCC) at the 1992 Earth Summit in Rio de Janeiro. In that agreement, 166 (now 194) nations acknowledged the need to limit the accumulation of GHGs in the atmosphere to a level that will "prevent dangerous anthropogenic interference with the climate system." 1

During that same period, emissions trading began emerging as a practical and increasingly popular policy tool to address pollution control, particularly with the successful phasedown of lead in gasoline and the creation of the acid rain trading program in the United States (Stavins 1998, Tietenberg 1985). On the international scene, the Montreal Protocol on Substances that Deplete the Ozone Layer, signed in 1987, laid clear groundwork for the idea of targets and timetables for emissions levels in different countries and included some emissions trading. It is therefore not surprising that there was considerable enthusiasm for using this tool to address climate change as countries grappled with how to meet their emissions objectives in the 1990s. Indeed, advocacy for international GHG emissions trading began in the late 1980s and early 1990s: The United States initially promoted it in the UNFCCC treaty negotiations, and the idea of joint implementation as an informal version of emissions trading ultimately appeared in the UNFCCC (Wiener 2001). ${ }^{2}$

This enthusiasm for emissions trading ultimately overcame various objections and led to the signing of the Kyoto Protocol in $1997 .^{3}$ The Kyoto Protocol was the first vehicle for emissions trading in GHGs-or what we term carbon markets. ${ }^{4}$ The Protocol set up a system of emissions limits for a basket of six GHGs for developed countries, mechanisms for those countries to trade emissions limits, and mechanisms to offset those emissions by financing emissions reductions in developing countries. Although the Kyoto Protocol itself has led to a very small number of trades directly among countries, the European Union and a variety of other jurisdictions have since pursued emissions trading to reduce their GHG emissions. Carbon markets are now the largest class of environmental or emissions trading markets in the world in terms of both volume and market value, by a very wide margin.

But how effective has emissions trading been at addressing climate change? What are the distinguishing features of trading in emissions of GHGs compared with, for example, conventional air or water pollution? What have we learned as carbon markets have been designed, implemented, operated, and revised? The purpose of this article is to answer these questions and to highlight new emerging issues that now need to be confronted. After 9 years of carbon market experience following the implementation of the EU Emissions Trading System (EU ETS) in 2005 (see Figure 1)—experience that includes growing market volumes, market value, and emissions coverage—at least part of the answer must be, yes, carbon markets can work effectively. However, important lessons and questions remain for current and future policy makers, analysts, and researchers.

\footnotetext{
${ }^{1}$ See Article 2 of the UNFCCC.

${ }^{2}$ Joint implementation refers to one nation financing (partly or in whole) an emissions reduction project in another nation.

${ }^{3}$ Objections included an early focus on emissions taxes in the European Union (Barrett 1998) as well as more general issues related to emissions trading (e.g., Sandel 1997).

${ }^{4}$ We use the term carbon market because $\mathrm{CO}_{2}$ is the dominant gas in terms of its overall contribution to global warming and because the units of trade are denominated in terms of $\mathrm{CO}_{2}$ equivalent.
} 


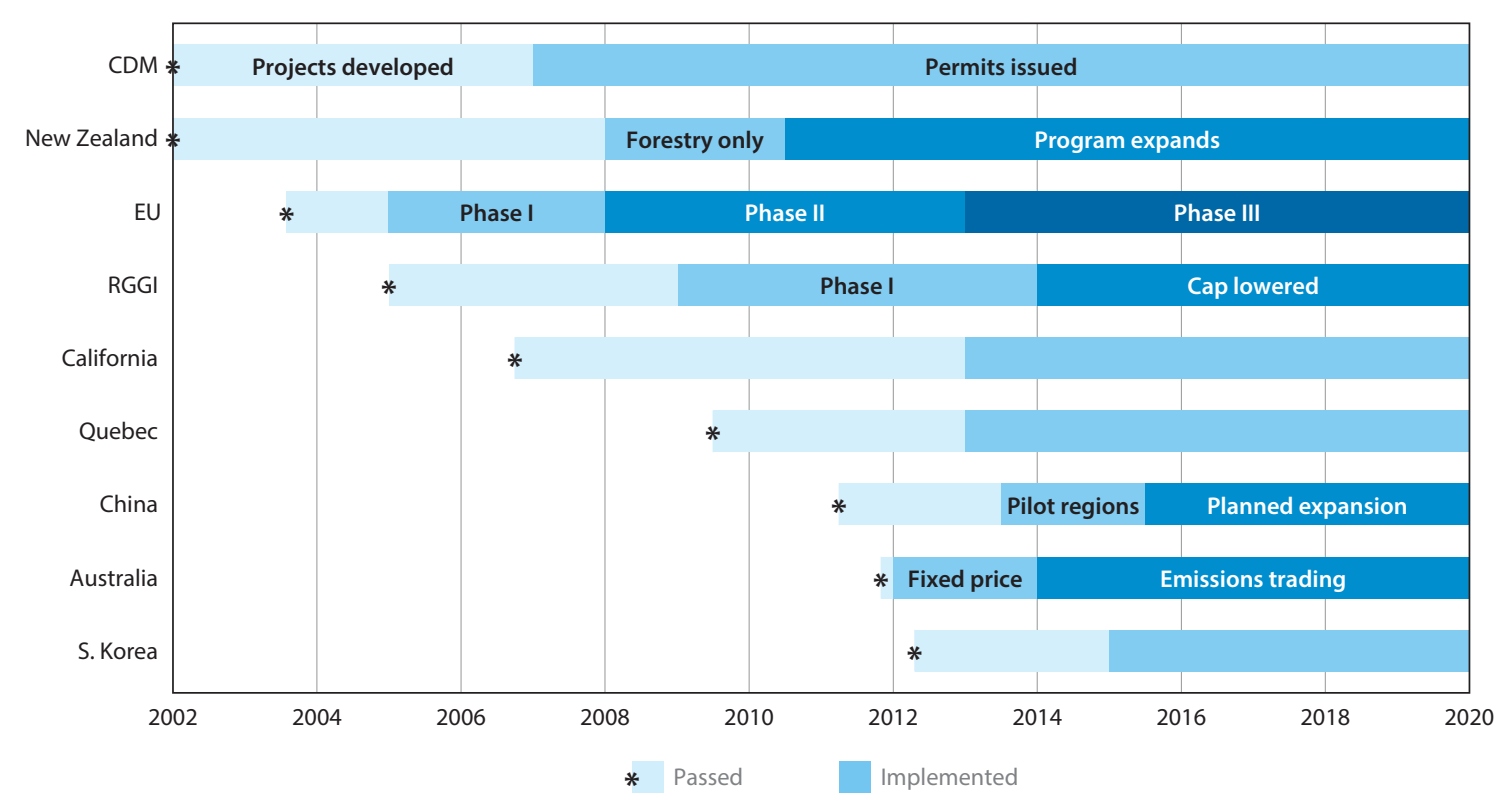

Figure 1

Timeline for selected GHG emissions trading programs. Abbreviations: CDM, Clean Development Mechanism; RGGI, Regional Greenhouse Gas Initiative.

The next section provides an overview of the normative theory of carbon market design, beginning with a description of some of the relevant attributes of GHGs. Section 3 discusses the design and implementation of actual emissions trading programs, whereas Section 4 describes and draws lessons from experience in the markets that have been created. Section 5 looks forward and describes key issues facing emissions trading policies now and in the future.

\section{NORMATIVE THEORY OF POLICY DESIGN FOR CARBON MARKETS}

A number of distinguishing attributes of the climate problem are relevant to the design of carbon markets and differentiate them from most other emissions or resource markets. The first is the global nature of the climate problem. $\mathrm{CO}_{2}$ and other GHGs are some of the few examples of global, uniformly mixed pollutants: Most GHG emissions throughout the world have the same consequences regardless of where they are emitted. ${ }^{5}$ Put another way, GHG emissions have exactly the same externality properties across countries that many conventional emissions have within a local jurisdiction. It is insufficient to control the GHG emissions from a particular source or region to reduce the risks to that region. This feature of the climate problem requires that, ultimately, an internationally coordinated approach be taken, with implications for carbon markets that make them unusual, if not unique, among environmental markets.

Second, many GHGs are long-lived stock pollutants, remaining in the atmosphere on the order of decades to centuries. The accumulated global atmospheric concentration of GHGs, rather

\footnotetext{
${ }^{5}$ Ozone-depleting substances are one other example. Aerosol GHGs, such as black carbon and sulfate, can have regional climate impacts.
} 
than the amount emitted at a particular time, is linked to global warming and climate change. Along the same lines, the capital stock that produces, distributes, and consumes GHGs also tends to be long lived; cars and major appliances typically last for more than a decade, whereas power plants and buildings last several decades. It is therefore important to keep in mind a long-term global perspective when one is addressing the climate problem, even when considering nearterm regional policies.

Third, although $\mathrm{CO}_{2}$ is the dominant GHG, there are numerous GHGs of varying potency (quantified in terms of the amount of heat energy trapped by a given amount of each gas) and longevity, from methane, with an average lifetime of 12 years, to sulfur hexafluoride, with a lifetime of 3,200 years.

Fourth, GHGs are pervasive in the economy, rather than being identified with a particular set of sources, sectors, or technologies. $\mathrm{CO}_{2}$ is a fundamental product of the combustion of fossil fuels (coal, oil, and natural gas) for energy production. Energy is used everywhere, and fossil fuels are the source of more than $80 \%$ of US and global energy consumption. As a consequence, the potential market size is much larger than other existing environmental markets. For example, in 2010, fossil fuel combustion accounted for approximately 32 billion metric tons of global $\mathrm{CO}_{2}$ emissions (Boden et al. 2013). The market value of 1 year of allowances for these emissions at $\$ 10$ /metric ton would be $\$ 320$ billion; at $\$ 25 /$ metric ton, it would be $\$ 800$ billion. The market value of allowances-the amount ultimately paid by consumers to whomever initially holds the allowances-represents an enormous cost to those paying and will likely be many times the actual cost of reducing emissions (Burtraw \& Evans 2009).

Fifth, uncertainty is pervasive. In part related to the long time frames associated with accumulated emissions and energy-using capital, uncertainty about climate risks, mitigation costs, and technology development creates additional challenges for policy analysis, construction, and implementation.

When placed in an economic paradigm, the above attributes of the climate problem have a number of implications for carbon market design. We discuss the most important of these in this section, including the importance of compliance flexibility for cost-effectiveness; the significance of benefit and cost features for efficient instrument design; and the link between allowance allocation, government revenue and use, distributional impacts, and international competition. For further details on several of these design issues, Aldy et al. (2010) provide a thorough review of the literature on designing climate mitigation policy.

\subsection{Cost-Effectiveness, Comprehensiveness, and Flexibility}

Cost-effectiveness, or achieving a given aggregate GHG mitigation target at the lowest possible cost, tends to be a top-tier concern for market-based policy design. To theoretically enable costeffectiveness (although not empirically guarantee it), the above characteristics tend to point to the design of carbon markets that have comprehensive coverage (i.e., across all gases, sectors, sources, and technologies), that take advantage of mitigation opportunities at a global scale, and that have a long-term time horizon and a structure that supports integrated decision making across time. This approach, sometimes referred to as "what, where, and when flexibility," underpins a normative tendency toward comprehensiveness and minimal barriers to trading opportunities.

"What flexibility" relates to the comprehensiveness of any carbon market. Theory guides design toward the inclusion of as many types of GHGs (e.g., $\mathrm{CO}_{2}$, methane, nitrous oxide, and fluorinated compounds), sectors (e.g., electricity, transport, industry, and agriculture), and technologies (e.g., fuel switching, carbon capture and storage, and forestry or other biosequestration) as is feasible. 
"Where flexibility" speaks to the significant variation in the costs of GHG mitigation across regions and countries. When one is designing a carbon market for any specific jurisdiction, it is important to consider the extent to which allowances from other jurisdictions or offsets will be accepted for compliance. Offsets refer to credits received for reducing emissions or for removing GHGs directly from the atmosphere (e.g., through forestry) that are not otherwise covered under a particular cap. Offsets can occur within or outside of the jurisdiction covered by an emissions cap. So long as the validity of such allowances or offsets can be established, cost-effectiveness would tend to point toward open trade in allowances across jurisdictions.

Finally, given the long-lived, stock pollutant nature of most GHGs, emissions on any particular day, month, or year are relatively inconsequential for climate impact; what matters is the accumulated volume in the atmosphere. As a result, allowing "when flexibility" through banking or borrowing of allowances across time tends to increase cost-effectiveness without additional harm to the climate. So long as the full range of mitigation options across space and time are available to the market, trading will in principle lead to a cost-effective allocation of pollution control actions through the elimination of opportunities for arbitrage.

\subsection{Efficiency and Instrument Design Under Uncertainty}

In addition to cost-effectiveness, which implies equalization of marginal pollution control costs across all potential mitigation options, overall economic efficiency requires balancing the expected marginal benefits and the expected marginal costs of GHG mitigation (Interagency 2013, National Research Council 2010). Such calculations present challenges given the aforementioned characteristics, particularly in terms of the valuation of emissions consequences over their relatively long lifetime in the atmosphere. In addition to the difficulty of estimating and monetizing climate change damages, economists are not in agreement over how to compare consequences over long periods of time (Aldy et al. 2010, Arrow et al. 2012, Interagency 2009, National Research Council 2010).

Economics has been more informative regarding the benefit-maximizing design than regarding the stringency of policy instruments. In particular, the economic literature on climate policy instrument choice under uncertainty (Newell \& Pizer 2003, Pizer 2002) points to the advantage of price-based instruments (i.e., a carbon tax) over quantity-based instruments (i.e., cap-and-trade) on the basis of a modified Weitzman-type argument (Weitzman 1974) and assuming that compliance has to be achieved on an annual basis. This work also shows that price-like modifications within a cap-and-trade program—ceilings and floors on the allowance price or adjusting the cap to accommodate cost shocks-could achieve the same outcome as a carbon tax (Murray et al. 2009, Newell et al. 2005). Recent work shows that cap-and-trade programs with banking provisions-which are included in virtually all such programs-could come close to the efficiency of a carbon tax under certain assumptions (Fell et al. 2012).

\subsection{Allowance Allocation: Equity and Efficiency}

As with other market-based programs, GHG allowances can be auctioned, allocated for free, or some combination of the two. Allowance allocation has distributional and efficiency consequences that can be large-on the order of hundreds of billions of dollars-given the sizable economic rents at stake. As noted above, because of the relatively small ratio of mitigation to emissions in most carbon trading regulations to date, payment of these rents tends to be the dominant distributional cost. 
In many key carbon-emitting sectors, we would expect competitive pressure to lead product prices to reflect carbon content, regardless of any free allocation to those sectors. ${ }^{6}$ Consequently, end users of energy would ultimately end up paying these rents. In turn, there could be significant distributional impacts to alternative free allocation approaches and formulas that distribute these rents, with implications for feasibility and equity across firms, income groups, regions, and generations.

Most arguments for free allocation (or earmarked uses of auction revenues) focus on the need to address an otherwise undesirable distribution of burden. Weighing against these distributional concerns is the prospect of using this revenue to offset other distortionary taxes. The literature tends to support the view that revenue-neutral full auctioning and the use of proceeds to lower other distortionary taxes offer a significant potential gain in efficiency relative to free allocation or lump sum redistribution of revenues (Aldy et al. 2010).

A third possibility is the use of auction revenues to support complementary GHG mitigation efforts—such as funding energy efficiency programs and technology research, development, and demonstration. Although there is no equity or efficiency gain, from a practical point of view, the use of carbon market revenue to support other GHG mitigation programs has appealed to policy makers and has been a prominent feature of proposed and implemented carbon markets.

\section{PROGRAM OVERVIEW AND KEY DESIGN CHOICES}

Carbon markets have been established at the international, national, and subnational levels, as highlighted in Figure 1. This section briefly summarizes the initial design choices in a variety of programs and markets and then compares elements along the key normative dimensions. Table 1 provides a summary of these elements. We describe major changes in specific markets, and the experiences that prompted these changes, in Section 4.

\subsection{Program Overview}

Carbon markets have emerged across a range of jurisdictions over the past two decades, with several new programs currently under development or in pilot phases. Program designers face a variety of choices regarding how to structure carbon markets, and past experience in early trading programs is shaping the design choices of new ones.

3.1.1. Kyoto Protocol. The Kyoto Protocol established the first nonvoluntary carbon market, committing certain nations to meet GHG emissions reduction targets and establishing a framework for allowance trading across international borders. However, the Kyoto Protocol has not led to an internationally liquid carbon market, and its future as a framework for reducing emissions is uncertain, with the second commitment period covering only approximately $15 \%$ of global emissions (Chacko 2012).

One enduring result of the Kyoto Protocol has been the establishment and execution of the Clean Development Mechanism (CDM) and Joint Implementation (JI) offset programs, which have seen robust activity and trading. CDM projects reduce emissions in developing nations, whereas JI projects come primarily from projects in the former Soviet Union. Both project types seek to encourage clean energy investment and learning while reducing emissions at low cost, and

\footnotetext{
${ }^{6}$ Exceptions to such pass-through may include utilities under cost-of-service regulation (in which such pass-through is prohibited) and industries facing strong international competition (and thus world prices).
} 


\begin{tabular}{|c|c|c|c|c|c|}
\hline 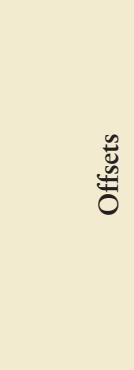 & 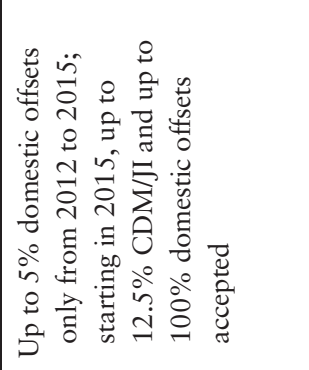 & 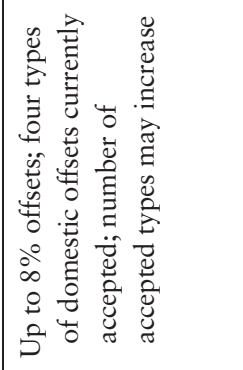 & 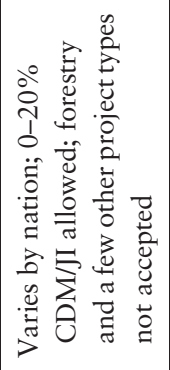 & 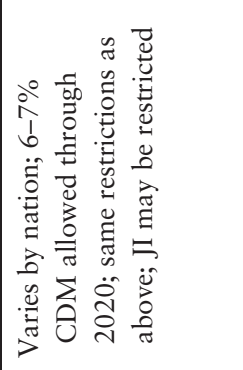 & 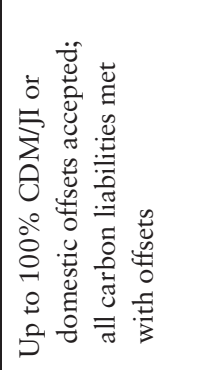 \\
\hline 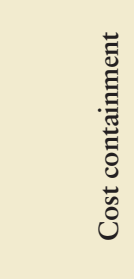 & 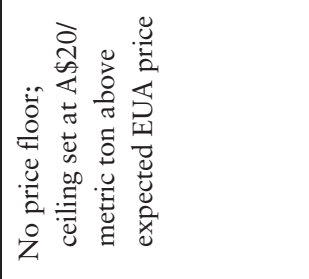 & 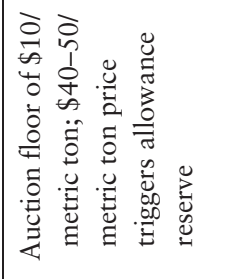 & 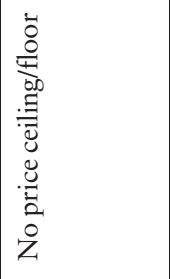 & $\begin{array}{l}\ddot{8} \\
\text { J } \\
\tilde{J} \\
0 \\
0 \\
z\end{array}$ & 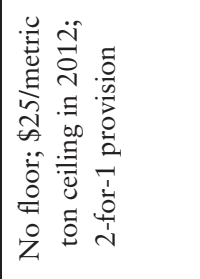 \\
\hline 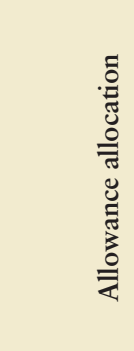 & 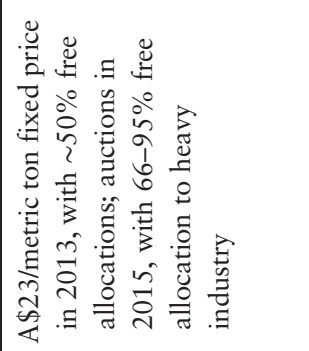 & 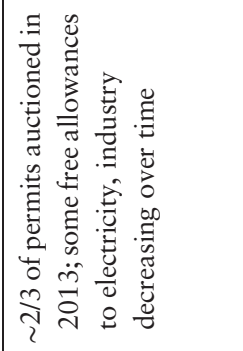 & 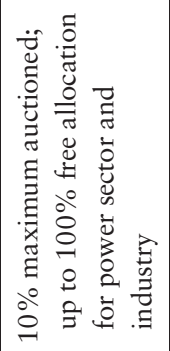 & 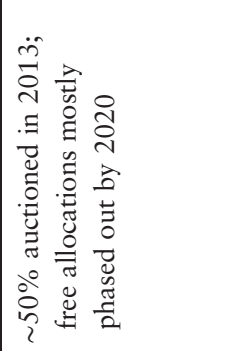 & 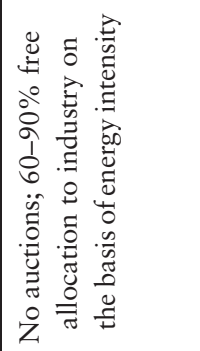 \\
\hline 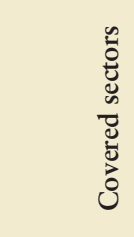 & 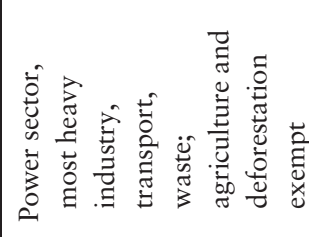 & 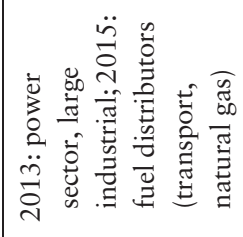 & 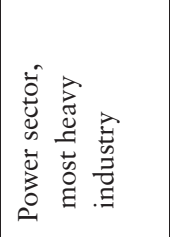 & 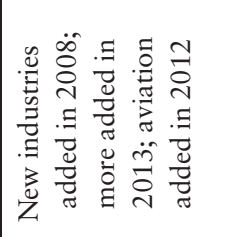 & 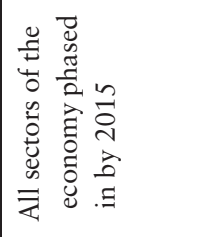 \\
\hline 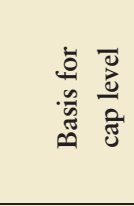 & 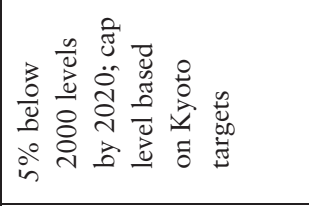 & 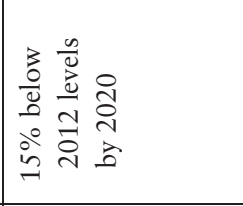 & 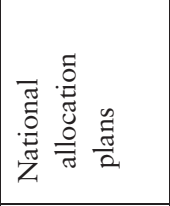 & 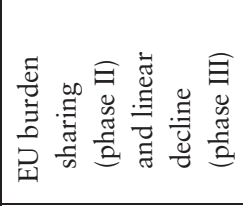 & 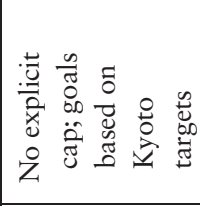 \\
\hline 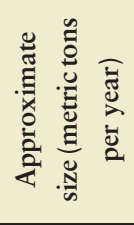 & 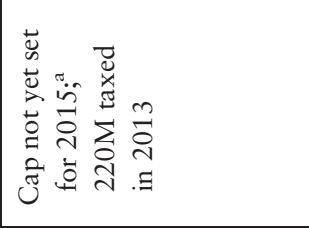 & 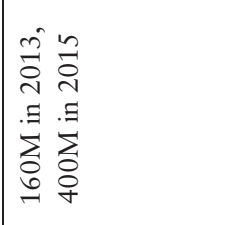 & तै & 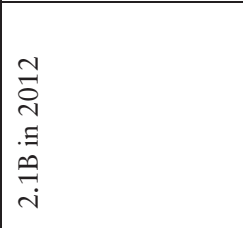 & 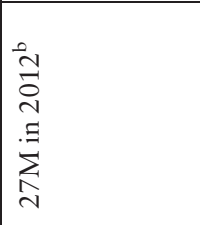 \\
\hline & 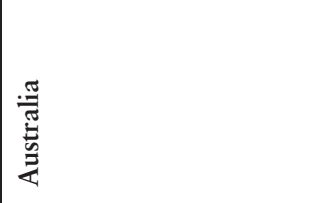 & 氶 & 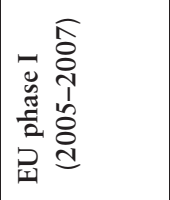 & 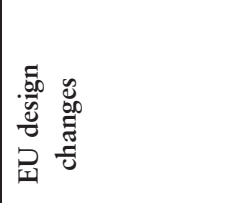 & 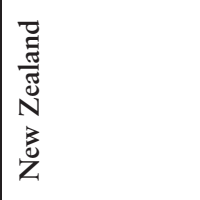 \\
\hline
\end{tabular}




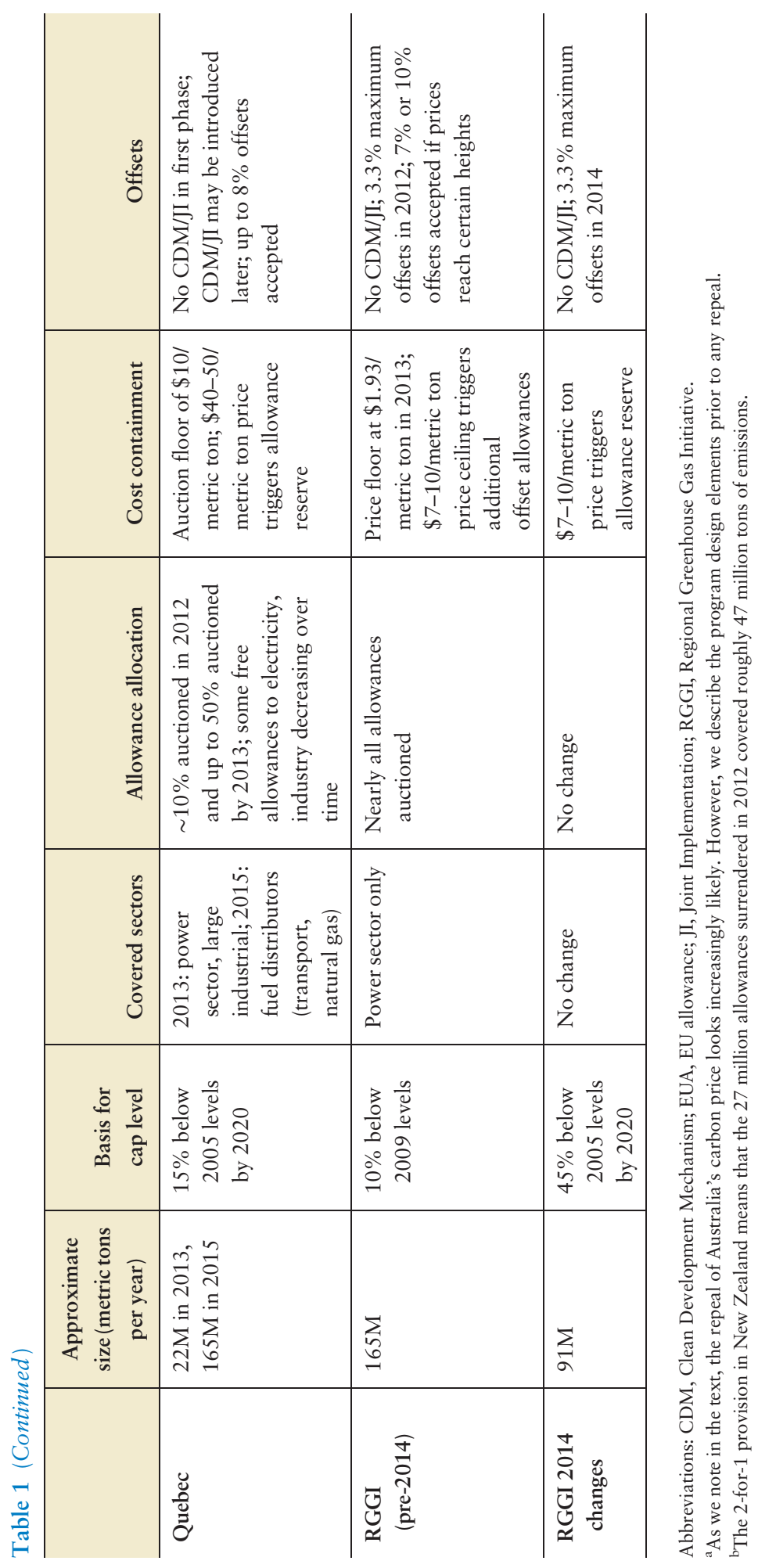


the resulting emissions credits are purchased by either nations or firms operating in certain markets—namely the European Union.

3.1.2. EU Emissions Trading System. Although most European nations favored a carbon tax going into the Kyoto negotiations, the European Union has created by far the world's largest carbon market: the EU ETS. The program's initial design was highly decentralized, with EU nations retaining significant discretion as to how to distribute emissions credits to different sectors of their economies (Kruger 2007). In the program's first two phases (2005-2007 and 2008-2012), the vast majority of allowances were allocated to firms free of charge. National plans also specified the number of CDM or JI credits available to market participants, with limits ranging from $0 \%$ to $20 \%$ (European Commission 2009). The EU ETS has no floor or ceiling price for allowances.

3.1.3. United States. The United States withdrew from the Kyoto Protocol, does not have a national emissions market, and is currently pursuing federal regulations that may or may not include market elements (Tarr et al. 2013). Nonetheless, two substantial subnational programs have developed.

First, the Regional Greenhouse Gas Initiative (RGGI, pronounced "Reggie") began in 2009, covers only the electric power sector, and comprises nine northeastern states. Nearly $100 \%$ of allowances are sold at regular auctions that include a price floor that varies over time. A second US market began in California in 2013. The program auctions roughly two-thirds of its allowances, initially covering the power sector and large industrial sources and accounting for roughly $37 \%$ of the state's GHG emissions. By 2015, the program will expand to cover $85 \%$ of GHG emissions, including transportation fuels (California Code of Regulations 2011). California currently allows emitters to meet up to $8 \%$ of their compliance obligations through domestic offsets, which are certified by state regulators. The program maintains a $\$ 10$ price floor for allowances and includes a tiered system of reserve allowances that can be tapped at prices of $\$ 40-50$ per allowance (Murray et al. 2009).

3.1.4. Canada. Canada ratified the Kyoto Protocol in 2002 but never passed comprehensive national legislation to regulate emissions. Many Canadian policy makers are reluctant to act on climate change without the United States taking comparable action. Nonetheless, several provinces have made independent efforts to reduce GHG emissions (Canadian Government 2011, De Souza 2011).

Quebec initiated a carbon market on January 1, 2013. The program will affect large industrial sources but will not affect most electricity generators because nearly all of Quebec's electricity comes from non-carbon-emitting hydropower. Quebec developed the system to be compatible with that of California, and the two programs linked together in early 2014 (we discuss linking in Section 5.1).

The resource-rich province of Alberta, which produces roughly 35\% of Canada's GHG emissions, has adopted an approach based on reducing GHG intensity (measured as GHG emissions per unit of economic output). Most allowances are allocated freely to emitters, and as of 2011, the program covered 106 facilities that accounted for roughly 45\% of Alberta's GHG emissions (Environmental Defense Fund and International Emissions Trading Association 2013). Although the program allows for allowance trading between firms, a significant allowance market has not emerged.

3.1.5. New Zealand and Australia. In 2008, New Zealand launched an emissions trading program that was designed to cover almost all emissions, with caps based on its 2008-2012 
commitment under the Kyoto Protocol. ${ }^{7}$ Given the country's size, New Zealand's program includes a relatively small number of large emitters and was built around the idea of linking to other markets such as the CDM. Industries facing international competition, horticulture, and fishing receive up to $90 \%$ free allocation. There is a ceiling price of NZ\$25, and there is no price floor (New Zealand Government 2012).

In Australia, major carbon emitters pay a fixed carbon price set by legislation, with a plan to allow market trading to set the price beginning in 2015. In August 2012, Australia announced that its program would link with the EU ETS, allowing emitters to surrender European allowances to comply with up to $50 \%$ of their requirements (Australian Government 2012, Reklev 2012). However, Australia's conservative party, which has made repealing the carbon price "the top priority" on its agenda, gained control of the parliament in mid-2013 and is moving in 2014 to repeal the carbon price (Australia Liberal Party 2012). At the time of this writing, the repeal of Australia's carbon price looks increasingly likely but has not yet been finalized. As such, the remainder of this article discusses Australia's program as if it were to be implemented as planned.

3.1.6. China. China, the largest aggregate emitter of GHGs, is developing a series of subnational carbon markets (Han et al. 2012), several of which launched in late 2013 and early 2014. The markets will cover roughly 700 million tons of $\mathrm{CO}_{2}$ per year and will be based on emissions intensity targets, with the eventual goal of reducing emissions by $45 \%$ per unit of GDP by 2020 (Reklev 2013). Recent reporting indicates that, although the programs are regional, China may intend to develop a nationwide market that is capable of linking with other national or regional markets (Stanway 2013). To date, China's primary contribution to international carbon markets has been as a developer of CDM projects, although China appears poised to become a more important market participant in the coming decades.

3.1.7. Other markets, including voluntary markets. Recent legislation passed in South Korea and Mexico has laid the groundwork for new national-level programs beginning in 2015. Programs are also under discussion in India, Japan, Vietnam, and Thailand, indicating an interest in carbon markets across much of Asia. Other emissions pricing proposals are currently under discussion or development in Brazil, Chile, and South Africa, among others (World Bank 2013).

Finally, voluntary carbon markets refer to a variety of private organizations that allow individuals or businesses to purchase offsets from emissions reduction projects. Since 2002, voluntary markets have grown from $\$ 43$ million in revenues to a peak of $\$ 705$ million in 2008 and stood at $\$ 523$ million as of 2012 (Ecosystem Marketplace and Bloomberg New Energy Finance 20082013). Dozens of organizations offer voluntary carbon offsets, and their standards for evaluating and monitoring GHG reduction projects can be less stringent than those used for the CDM or JI. Among the benefits of less stringent standards are reduced bureaucracy and the potential for lower project costs; however, weaker standards may also lead to the certification of projects that do not provide their stated benefits (Benessaiah 2012).

\subsection{Key Normative Design Choices}

Carbon market designers face a variety of choices with important implications for the costeffectiveness, economic efficiency, and distributional effects of emissions trading programs.

\footnotetext{
${ }^{7}$ New Zealand has not renewed its commitments under the 2013-2020 period of the Kyoto Protocol. However, its carbon market will continue to seek reductions through negotiations within the UNFCCC framework.
} 
These choices inevitably involve trade-offs and can create challenges at the technical and political levels.

3.2.1. Cost-effectiveness. Our earlier discussion focuses on the need for "what, where, and when flexibility" to maximize cost-effectiveness. "What flexibility" encourages the inclusion of as many emissions sources as possible in a trading program. To date, most programs have focused initially on large stationary sources such as power plants and industrial factories. Such sources have relatively low monitoring costs and-from a political perspective-are often easier to target for regulation than sources such as transportation. Heavy industrial processes (e.g., cement, aluminum, and lime) are covered by every major system other than RGGI. Transportation emissions are covered (or will be covered) in New Zealand, Australia, California, and Quebec.

"Where flexibility"-which encourages flexibility to shift mitigation efforts across jurisdictions-is evolving. Above, we discuss linkages between programs in Quebec and California, on the one hand, and proposed linkages between programs in Australia and the European Union, on the other. Given the observation that reductions in developing countries offer the largest potential for low-cost mitigation opportunities (Weyant \& Hill 1999), we might expect to see a larger focus on international emissions offsets than on linkages among developed country jurisdictions. Indeed, although specific provisions and restrictions vary, all programs to date include or envision including international offsets in some capacity. Offsets from the CDM and JI played a major role in the initial phases of the EU ETS, with some member states allowing up to $20 \%$ of emissions reductions to be met with offsets (Ellerman et al. 2010). New Zealand has no limit on offsets.

Some programs emphasize local rather than international offsets. Offset projects based within a program's borders ensure that the associated investment stays close to home, although the projects may cost more than international opportunities, implying higher costs for locally regulated industries.

"When flexibility" encourages flexibility to shift emissions over time among regulated sources. With few downsides, banking provisions have been included in every major program, although borrowing provisions have been less widely adopted despite the potential for economic benefits (Fell \& Morgenstern 2009).

3.2.2. Efficiency and uncertainty. Economic efficiency—as opposed to cost-effectiveness—requires balancing costs and benefits and emphasizing relatively stable prices. There is no explicit balancing of costs and benefits in any program, and jurisdictions have taken a variety of approaches to setting reduction targets and measuring progress. However, many programs have included pricelike elements that improve efficiency, as noted above. Australia and New Zealand incorporate a price ceiling. California, Quebec, and RGGI have price floors. California and Quebec also include a tiered system of reserves, although the effectiveness of such reserves as a ceiling has been questioned (Bailey et al. 2012).

3.2.3. Allocation. After an early tendency to provide free allocations, new programs and revisions to existing programs have moved toward auctioning allowances. However, almost no program has explicitly directed auction revenues to be used to cut other distortionary taxes, as advocated on efficiency grounds, with the exception of Australia (and British Columbia, which has a carbon tax and has no plans for a carbon market). In many programs (e.g., RGGI and those of Alberta, Australia, and California), governments put a share of revenues from auctions toward projects such as renewable energy, carbon capture and storage, and energy efficiency.

Where there has been free allocation, the focus has tended to be heavy industry, particularly those firms facing competition outside the regulated region. Fearing economic dislocation, 
governments continue to give substantial free allocations to such firms. In every trading program that includes heavy industry, trade-sensitive industrial sectors receive up to $95 \%$ free allocation. When free allocation has gone to firms not facing competition outside the regulated region, they generally pass along the opportunity costs of freely received allowances, reaping windfall profits, a topic we return to below.

\section{MARKET EXPERIENCE AND LESSONS}

Having explored the initial design features associated with different carbon markets, we now turn to market experience and evolution. We focus on the EU ETS, CDM, and RGGI, for which there are at least several years of data, but we also include recent information on New Zealand and California.

Figures 2 and 3 provide basic information on carbon prices and volumes. Carbon prices in the EU ETS and CDM-the two largest markets—have generally fallen since 2008 in response to the global economic slowdown. Nonetheless, trading volumes have remained robust. ${ }^{8}$ Although new markets in California and China will rival the EU ETS in pure volume of allowances, the EU ETS has dominated the marketplace to date, with far greater volumes, liquidity, and price volatility than any other market. The EU ETS is also the largest outlet for CDM and JI credits. Additionally, the EU system is the only one in which a significant secondary market has developed, with market participants buying and selling standardized contracts up to 5 years in advance on a variety of exchanges.

\subsection{Lesson: Positive Prices Imply Emissions Abatement (but How Much Is Unclear)}

The mere presence of a consistently positive price on carbon suggests that carbon markets are having at least some impact on behavior with regard to emissions levels. Program design, underlying fuel prices, and larger economic forces affect the behavior of market participants, but primarily due to the youth of the EU ETS and other programs, research on the effect of each of these three variables relative to the carbon price remains limited.

One way to approach the abatement question is to estimate emissions reductions on the basis of elasticities derived from related analyses. A rough analysis of a variety of modeling projections in the United States suggests emissions semielasticities of $0.0015-0.0035$ per dollar in the year 2020 (Fawcett et al. 2009, Newell et al. 2014). That is, for each $\$ 10 /$ metric ton increase in the price of US $\mathrm{CO}_{2}$ allowances, emissions in 2020 would be between $1.5 \%$ and $3.5 \%$ lower compared with a scenario with no price on $\mathrm{CO}_{2}$ emissions. If similar economic dynamics are at play in the EU ETS, the program's phase I average allowance price of \$16/metric ton would suggest that emissions fell between $2 \%$ and $6 \%$ compared with a business-as-usual (BAU) scenario.

Existing research falls in line with this estimate. Empirical research on phase I of the EU ETS suggests that during 2005-2007, emissions fell by 2-5\% compared with a BAU scenario (Anderson \& Di Maria 2011, Ellerman et al. 2010). Because phase II of the ETS only recently concluded, we lack empirical research on abatement for 2008-2012. However, by using the semielasticities noted above, the $\$ 20 /$ metric ton average price of EU allowances (EUAs) from 2008 through midyear 2012 implies a reduction of 3-7\% compared with a BAU scenario with no emissions trading system in phases I or II. With prices hovering at approximately $€ 5$ through 2013 , the potential for emissions reductions will likely be significantly reduced if prices remain low.

\footnotetext{
${ }^{8}$ Reports indicated a $23 \%$ decline in EU ETS volumes in late 2013 compared with a year earlier. This decline may be connected to a continuing shift from brokers to exchange-based trading (Szabo 2013).
} 


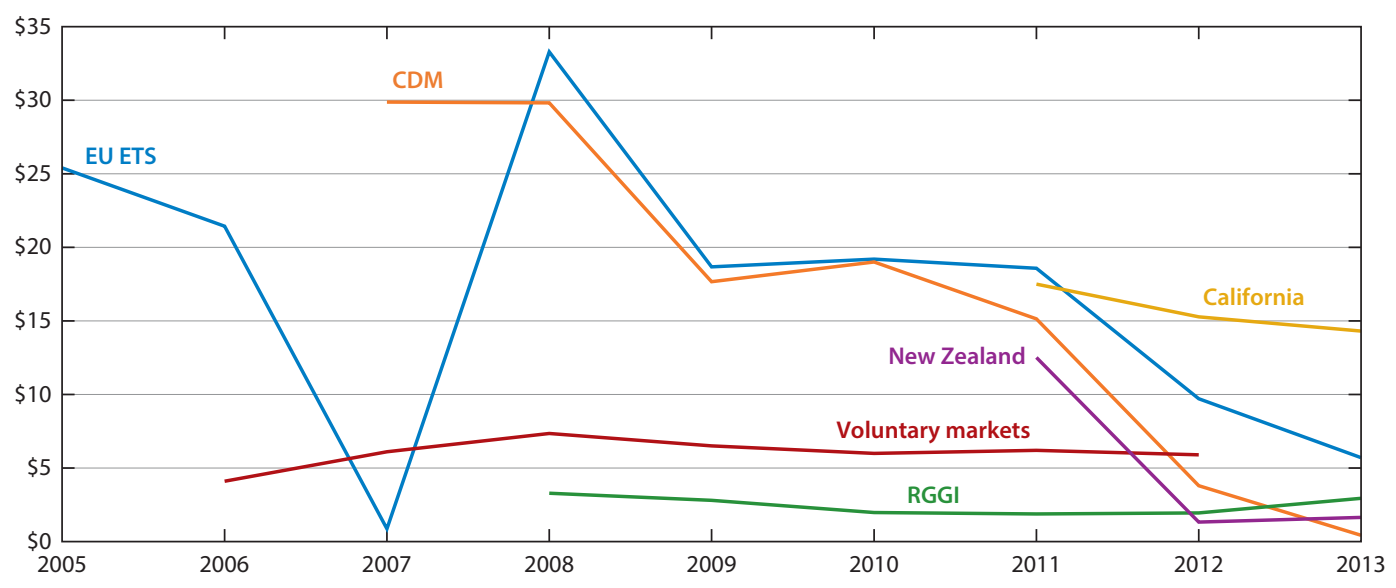

Figure 2

$\mathrm{CO}_{2}$ prices (annual average price per metric ton $\mathrm{CO}_{2}$, nominal US\$). Exchange-traded prices are through August 29, 2013, as reported by the following sources: Point Carbon (http://www.pointcarbon.com/news/marketdata/euets/forward/eua/), RGGI COATS (http://www.rggi.org/market/tracking/coats-platform), and Ecosystem Marketplace and Bloomberg New Energy Finance (2008-2013). Abbreviations: CDM, Clean Development Mechanism; EU ETS, EU Emissions Trading System; RGGI, Regional Greenhouse Gas Initiative.

A key question-and potential criticism — of current market-based policies is the degree to which they encourage long-term investment in new technologies rather than solely short-term fuel switching and energy conservation. Much has been written about the importance of long-term investment to address climate change and the potential effectiveness of market-based policies to drive it (Jaffe et al. 2002, Newell 2010). However, markets for $\mathrm{CO}_{2}$ may be too new to fully inspire the long-term confidence to make those investments, and early research into the EU ETS suggests that such investments may be limited (Calel \& Dechezleprêtre 2013, Leiter et al. 2011). In the case of RGGI, emissions fell well below the cap by late 2012 due to fuel switching and weak economic growth, which likely limited investment in long-term emissions reductions. In the CDM, which was partly intended to deploy existing technologies to developing nations, innovation has been less of a focus.

\subsection{Lesson: Without Banking, Prices Can Crash}

The first release of actual EU ETS emissions data in 2006 showed emissions levels charting a course well below their phase I cap. Because EUAs in phase I could be used only between 2005 and 2007, an oversupply of allowances meant that prices were likely to drop-and drop they did. ${ }^{9}$ In the first quarter of 2006, spot EUAs traded at $€ 25 /$ metric ton. By the final quarter of 2007 , spot prices were essentially zero, at $€ 0.06 /$ metric ton (see Figure 2).

This precipitous drop did not represent the underlying value of carbon mitigation, nor was it solely a problem of limited data; rather, it reflected the inability of market participants to bank allowances for use in future phases. Had emitters been able to use their remaining phase I EUAs in phase II, prices would still have dropped in response to news of a current-period oversupply but would not have approached near-zero levels. The rationale for not allowing banking was the

\footnotetext{
${ }^{9}$ Although 2005-2007 EUAs could not be banked, CDM credits could be moved forward. However, few CDM credits had up to this point been issued.
} 


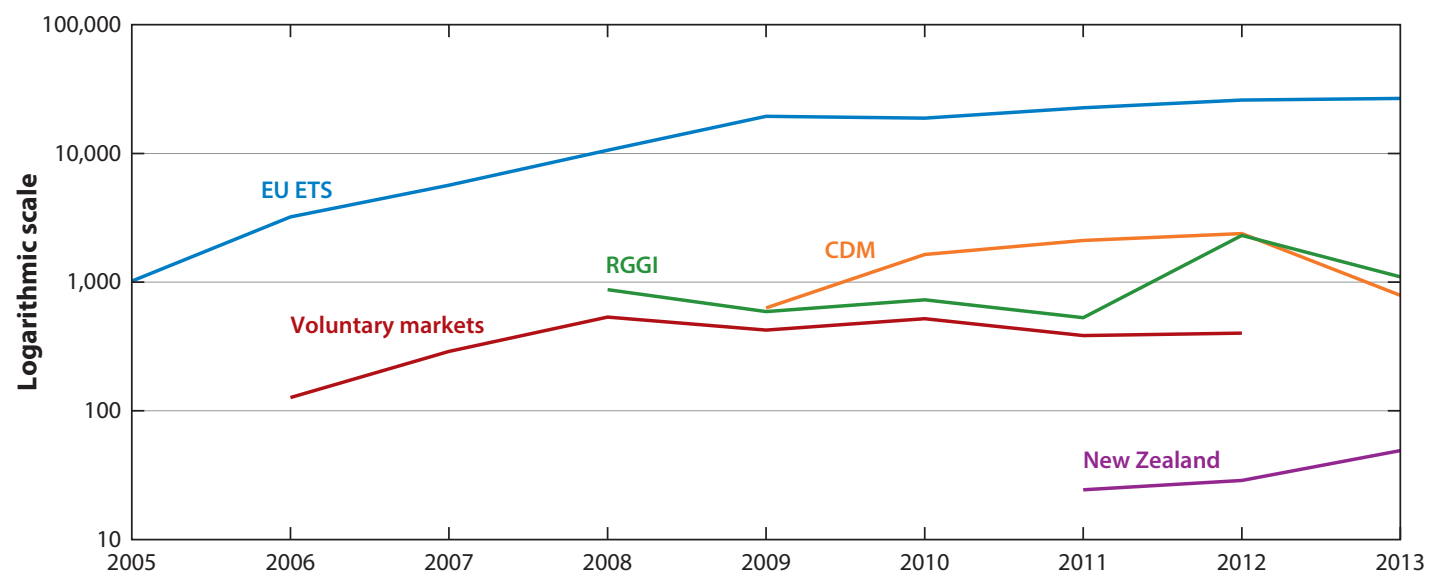

Figure 3

Volume of $\mathrm{CO}_{2}$ allowance trades (daily average). Exchange-traded prices are through August 29, 2013, as reported by the following sources: Point Carbon (http://www.pointcarbon.com/news/marketdata/euets/forward/eua/), RGGI COATS (http://www.rggi.org/ market/tracking/coats-platform), and Ecosystem Marketplace and Bloomberg New Energy Finance (2008-2013). Abbreviations: CDM, Clean Development Mechanism; EU ETS, EU Emissions Trading System; RGGI, Regional Greenhouse Gas Initiative.

desire to separate phase II, which coincided with the first Kyoto compliance period, from the phase I trial period-but the consequences of this decision were clear. Spot prices for phase I allowances approached zero even while contract futures prices for phase II EUAs hovered above €20/metric ton. The European Commission, as well as designers of all other existing and proposed programs, now allows unlimited banking of allowances between phases.

An emerging question is exactly how much banking an emissions trading system can (and should) support. Analyses of the failed Waxman-Markey bill suggested that by 2022 (10 years after trading's hypothetical start date), firms would have accumulated 7-12 billion metric tons of banked allowances, 140-240\% of the program's 2022 cap (Energy Information Administration 2009). Recent EU ETS estimates suggest that market participants in 2012 were banking nearly 2.5 billion allowances, roughly $119 \%$ of phase II's annual cap, for carryover into phase III (Neuhoff et al. 2012). A large volume of banked allowances may make current prices more sensitive to changing future expectations, a topic we return to in Section 5.2.

\subsection{Lesson: Free Allocation in Competitive Markets Does Not Help Consumers}

Every major carbon market allocates at least some free allowances to heavy industry and, in some cases, to power generators. In phase I of the EU ETS, the program allocated a large share of allowances to the power sector at no charge, due to government concern about a rise in consumer electricity prices and due to calls from industry. In competitive markets such as Germany, power generators passed along the opportunity costs of these free allowances to their customers, allowing generators to extract rents roughly comparable to their proportion of freely allocated allowances (Ellerman et al. 2010, Sijm et al. 2008). Put simply, power companies effectively charged customers for permits they had received for free.

This predictable market outcome demonstrated that free allocation did not necessarily protect consumers but did have distributional and political consequences (Gow 2006, Harrison 2009). The European Commission responded by limiting free allocations and increasing the proportion of allowances sold at auction. Because some industrial sectors face significant international 
competition, many industrial firms continue to receive substantial free allocations in the EU ETS. In contrast, EU power generators receive limited free allowances, and only in specified nations.

\subsection{Lesson: There Have Been No Significant Competitiveness Impacts (at Least at Low Prices)}

In the absence of a global regime, reduced economic competitiveness of covered sectors is often mentioned as a key concern for carbon taxes or emissions trading programs. Two distinct issues arise in this context. First, an emissions trading program entails economic costs and can redistribute economic activity—both jobs and capital—away from regulated sectors, particularly emissions-intensive manufacturing. These costs and redistribution are economic issues. In addition, some of this manufacturing activity may shift to unregulated jurisdictions, with emissions reductions reappearing in another region or nation. This potential shift amplifies the economic issues and creates the environmental issue of emissions leakage. If significant, leakage draws into question the underlying environmental rationale for emissions pricing within a particular region. However, a review of the (limited) empirical literature indicates that, at least for the early phases of the EU ETS and RGGI, competitive losses and leakage appear to have been small in the few sectors where it has occurred.

Ellerman et al. (2010) find "no observed impact" on competitiveness in the oil refining, cement, aluminum, or steel sectors during phase I of the EU ETS. Demailly \& Quirion (2008) find that phase I of the EU ETS created only a small loss of competitiveness in the iron and steel sectors. Lacombe (2008) finds a similar limited impact on the EU refining sector during phase I. Reinaud (2008), analyzing the EU aluminum sector, finds no statistical evidence of negative competitiveness impacts from the program but notes that information gaps remain. Most recently, a government-commissioned report finds no evidence of relocation but some anecdotal evidence that investment flows have shifted out of Europe (ECORYS 2013).

If the relatively low estimates from the European Union are accurate, these minimal competitiveness impacts and leakage rates may reflect the modest emissions reduction target under the first phase of the EU ETS. Additionally, uncertainty over emissions reduction policies around the world may delay firms from making decisions on relocating, as firms may expect GHG policies to come into effect in a growing number of jurisdictions. These observed competitiveness impacts and leakage generally fall below the levels predicted by some analyses of emissions pricing in the United States (Aldy \& Pizer 2009, Fischer \& Fox 2009, Ho et al. 2008, Interagency Competitiveness Analysis Team 2009).

Leakage and competitiveness issues in RGGI have also been a concern. Because RGGI states operate in an electricity market that is integrated with power markets in non-RGGI states, the potential for leakage in the power sector clearly exists. Some modeling suggests leakage rates ranging from $28 \%$ with $\$ 3$ allowance prices to $90 \%$ with $\$ 7$ allowance prices (Chen 2009, Kindle et al. 2011, Wing \& Kolodziej 2009). However, low carbon prices resulting from a weak economy and low natural gas prices appear to have prevented extensive leakage in RGGI (Kindle et al. 2011).

\subsection{Lesson: Offsets Can Work, but They Are Complex}

The Kyoto-established CDM and JI mechanisms have supported tens of thousands of emissions reduction projects. We focus here on the CDM, as CDM projects outnumbered JI projects by more than 12 to 1 from 2007 to 2011 (Fenhann 2012).

For offsets to truly reduce emissions, credits can be given only to projects that would not have occurred were it not for the offset credit program, thereby providing additionality. Although much 
research indicates that the CDM has resulted in real emissions reductions, a variety of studies describe cases in which nonadditional projects received credits under the program (Elsworth \& Worthington 2010, Lambert 2011, Wara 2008, Zhang \& Wang 2011). The most problematic project type in the past has involved the destruction of HFC-23, a refrigerant that is used in industrial processes and that has roughly 10,000 times the global warming potential of $\mathrm{CO}_{2}$ (UNFCCC 2012). Because of this high global warming potential, projects that reduce HFC-23 receive large numbers of credits. Lambert (2011) finds that inadequate baseline measurements helped create a perverse incentive, encouraging HFC-23 emitters to temporarily increase their emissions and allowing them to later reduce HFC-23 output and claim thousands of valuable credits. In the wake of such research, the European Commission voted to disallow credits from projects destroying HFC-23.

The CDM was envisioned as more than just an offset program-it was designed to speed broader development objectives, such as economic growth and technology transfer. However, the achievement of these goals remains uncertain (Dechezleprêtre et al. 2008, Lecocq \& Ambrosi 2007, Olsen 2007, Popp 2011, Schroeder 2009, Sutter \& Parreno 2007).

It is impossible to conclude a discussion of offsets without noting the collapse of the CDM market at the end of 2012. After remaining in the $€ 10-15$ range for most of 2009, 2010, and the first half of 2011, CDM prices fell steadily to less than $€ 1$ in late 2012 and hovered at approximately $€ 0.50$ through most of 2013 and early 2014. This fall has been ascribed to a weak EU ETS market, to increased limitations on the use of CDM credits in the EUETS, to uncertainty about future demand, and to increasingly robust supply—issues that will need to be sorted out for investors to continue to have confidence in offset markets.

\section{THE FUTURE OF CARBON MARKETS: NEW ISSUES}

In the late 1990s, most intellectual and stakeholder debate focused on a single global trading program as the primary vehicle to address global climate change. ${ }^{10}$ Today, that form of top-down global program seems unlikely, if not impossible. Instead, we see a multiplicity of regional, national, and subnational programs emerging. Moreover, we now have real experience with carbon markets. At the same time, the future of climate change policy in the United States-the largest developed country emitter and the original protagonist of emissions trading-is uncertain. The current trend in the United States is traditional, sector-by-sector regulation at the federal level coupled with state- and regional-level carbon market initiatives. When and if a more comprehensive US policy will emerge are unclear. Furthermore, we do not know whether that policy will be in the form of an emissions trading program, an emissions tax, a tradable performance standard, or something else. These developments raise new issues that received little attention in the previous literature and that in some cases were not fully anticipated or understood during the design of existing carbon markets.

\subsection{Linking Carbon Markets}

Front and center in the new discussion of carbon markets are how, whether, and when different markets can be linked so that regulated entities in one jurisdiction can use allowances or credits from another jurisdiction for compliance, and possibly vice versa (Jaffe et al. 2009). This

\footnotetext{
${ }^{10}$ Hahn \& Stavins (1999), for example, consider how an international trading system will interact with domestic policies that may or may not involve emissions trading.
} 
possibility is exemplified by the link between California and Quebec in early 2014. Previous negotiations over a link between Australia and the European Union have essentially ended as Australia plans to wind down its carbon price. The RGGI program is also a linked system: Each state in RGGI has regulated emissions within its own jurisdiction, using its own distinct legal authority. Under those same regulations, allowances from other RGGI jurisdictions are also simultaneously recognized.

There are a variety of possible motivations for these linkages: achieving cost savings and gains from trade, increasing domestic market liquidity and stability, and creating momentum for global action, among others. At the same time, there are challenges to linking, most notably the risk to environmental integrity, the need to harmonize features (and the corresponding loss of sovereignty over program design), the need to evaluate appropriate cap levels, and the distributional consequences of higher (or lower) prices.

Much of the academic work on linking has focused on the mutual gains to trade. Indeed, the early analysis of the Kyoto Protocol focused on how much cheaper a global trading system would be compared with a collection of autarkic systems (Weyant \& Hill 1999). As domestic emissions trading proposals began incorporating features like price ceilings, additional work showed that certain features in one system could lead to increased emissions if two systems were linked (Fischer 2003). As linking discussions have moved forward, researchers have begun to think about exactly which features have to be aligned, and which do not, to avoid such issues (Burtraw et al. 2013, Mace et al. 2008, Tuerk et al. 2009).

Recent work has also focused on different ways that systems might link (Mace et al. 2008, Mehling \& Haites 2011). In practice, linkages may be one way or two way. In a one-way linkage, credits in one system can be used for compliance in another, but not vice versa. In a two-way linkage, both systems mutually allow the other's credits to be used for compliance. ${ }^{11}$ It is useful to further distinguish within each direction of linkage between the buy- and sell-linkage decisions and how they relate to the aforementioned concerns (any buy-linkage decision by one actor represents a sell-linkage decision by the seller). A buy linkage represents the decision by one trading system to accept allowances or credits offered for sale by another system. Sell linkages represent an implicit or explicit decision by one jurisdiction to allow or encourage other jurisdictions to use its allowances or credits.

Concerns about environmental integrity typically arise in the program expecting to become a buyer. Concerns about harmonizing features can arise in either system, depending on which party has more power in the linking negotiation; this is frequently a function of the relative market size. For example, the European Union set the terms for Norway, Iceland, and Liechtenstein to enter the EU ETS, and California largely set the terms in the recent Quebec-California linkage. Meanwhile, the CDM as a seller of credits remains independent, although the European Union and other buyers have unilaterally set certain conditions on the kinds of CDM credits they will accept.

One might expect internal distributional concerns to arise in a jurisdiction expecting to become a seller. For the buying system, linking lowers prices with the same environmental outcome. Lower prices generally mean less redistribution among various market agents. For the selling system, however, linking raises prices. There are still gains to trade for the selling system as a whole, but higher prices generally mean more redistribution among buyers and sellers within the selling system.

Yet another question is how delinking might work (Pizer \& Yates 2013). In May 2011, New Jersey governor Chris Christie announced that his state would exit the RGGI program at the

\footnotetext{
${ }^{11}$ Linkages can also be indirect: If A links to B and B links to C, A will have an indirect linkage with C. For example, A's credits can be used for compliance in B, freeing up B's credits to move to C. The net result would be credits leaving A and entering C.
} 
end of 2011. Although one might imagine that such an action would have disrupted the RGGI market, New Jersey's withdrawal proceeded smoothly. ${ }^{12}$ This process begs the question of what can be learned from this experience, which may become more common as linking expands.

\subsection{Policy Revision and Uncertainty}

A second emerging issue for carbon markets has been uncertainty stemming from the central role of policy. Because governments create emissions markets (excluding voluntary markets), their decisions-or debate over decisions-to change policy have the potential to dramatically affect those markets.

For example, as the EU ETS faces low prices in its third phase, the European Commission has moved forward with a delay in auctioning millions of EUAs, which has somewhat supported short-term prices. However, unless those allowances are retired permanently, they will eventually come back into the market, suppressing future prices. RGGI saw a decrease in the size of its market when New Jersey suddenly withdrew from the program in 2011. The program has also revised the level of its cap, with a $45 \%$ reduction taking effect in 2014, bringing the cap more in line with actual emissions levels and boosting allowance prices. As mentioned above, Australia's new government has vowed to eliminate that country's proposed emissions trading program. In New Zealand, rules were revised to allow one allowance to be surrendered for two metric tons of emissions during a transition phase to cope with the global economic downturn, although this transition phase appears to be continuing indefinitely (Fallow 2009).

Unlike conventional regulation, in which the financial consequences of policy revisions are limited mainly to impacts on the value of physical investment, revisions to carbon market rules (or carbon taxes, for that matter) affect the value of financial liabilities associated with emissions. Such revisions also affect the value of financial assets-existing allowances; government receipts from future allowance sales; or, in the case of free allocation, the value of future free allowance allocations. Banking provisions in most programs lead to all these effects being priced in the market much sooner: Although policy changes may not take effect for several years, any expected change in future allowance prices immediately affects current prices (Murray et al. 2009). ${ }^{13}$ Moreover, market prices can move on mere speculation over policy changes.

This interrelationship between policy revision and market prices, coupled with the unpredictable behavior of governments and the vagaries of market sentiment over that behavior, implies that policy revision can create considerable price volatility. This price volatility, in turn, has real costs, as near-term mitigation efforts fluctuate in response to those prices. What do these market impacts imply for the broader issue of policy design and revision? Although this is an important area for further work, we offer a few observations here.

First, policy revision must still happen. Coupled with the interdependence of policies in different jurisdictions, revisions to carbon markets are essential to long-term efficiency (Murray et al.

\footnotetext{
${ }^{12}$ For example, Maryland's surprise lack of participation in the first year of the $\mathrm{NO}_{x}$ trading program in the United States caused a price collapse in 1999 (Burtraw \& Szambelan 2009).

${ }^{13}$ This price dynamic is a significant difference between pollution taxes and emissions trading. Changes in future tax rates affect future liabilities, whereas changes in future emissions trading rules, through price arbitrage, can affect the current price and hence immediate liabilities. Both types of changes can affect current asset values, and both can be influenced by speculation. However, this distinction of price arbitrage in carbon markets, but not with carbon taxes, implies that jurisdictions have more latitude to attenuate the financial consequences of future policy changes by using carbon taxes and announcing changes well in advance.
} 
2009). Although markets and affected stakeholders may crave certainty, governments cannot guarantee certainty where it does not fundamentally exist.

Second, governments should strive for transparent and orderly policy revisions. Many government agencies, from central banks to regulators to courts, regularly make decisions that have significant market consequences. Regulatory agencies, courts, and legislatures need to pursue market-sensitive decisions in a way that gives all market participants equal access to information as well as advance notice of the sequence and timing of the decision process.

Finally, and most relevant to the topic of policy design, emissions trading policies can be made more amenable to revisions. For example, one legislative proposal in the United States would have implemented a schedule for 5 -year reviews and revisions, with presidential submission of recommendations shortly after the compliance year ended and expedited congressional action within 6 months. ${ }^{14}$ California appears to be taking a similar approach, announcing its timeline for policy planning well in advance (California Air Resources Board 2013). This approach stands in contrast to the 2013 debate in the EU parliament, where votes on revisions to the EU ETS have spurred significant market movements, highlighting the issues created by uncertain policy conditions.

Another option is to put decisions about market-sensitive policy changes, particularly those balancing emissions mitigation and cost, into the hands of an independent oversight entity. This role would be similar to that of a central bank seeking to balance economic growth and inflation. ${ }^{15}$ Such an entity would be responsible for periodic reviews and changes to the emissions limit or other rules and would have the flexibility to act deliberatively and outside the explicitly political sphere of legislatures. Given experiences with central banks and monetary policy, this approach has some appeal. However, the continuing divergence of views about the appropriate level of response to climate change—even among experts—would create challenges.

\subsection{Alternative Policies and Comparability}

The range of policy responses emerging in various jurisdictions suggests that we are heading not only into a world of decentralized, bottom-up emissions trading regimes with varying rules, but also into one in which emissions trading may often take a back seat to emissions taxes or more traditional regulation. For example, policy-related emissions reductions in the United States over the past few years have arisen from tighter regulations on automobile fuel economy and tailpipe GHG emissions, renewable electricity capacity additions associated with federal and state subsidies and mandates, and (the expectation of) new power plant emissions regulations under the Clean Air Act. ${ }^{16}$

This diversity of policy approaches was not altogether unexpected. Under the Kyoto Protocol, there is no requirement to implement a domestic emissions trading program. The EU ETS covers only roughly half of European emissions, with traditional regulation or taxes used elsewhere. And in the United States, the competitiveness provisions of the Waxman-Markey bill did not seek to require trading partners to have an emissions trading program but would have required only a "nationally enforceable and economy-wide greenhouse gas emissions reduction commitment for that country that is at least as stringent as that of the United States."17

\footnotetext{
${ }^{14}$ Low Carbon Economy Act of 2007, S. 1766, 110th Congress. See $\S 102(b), \S 501(b)$, and $\S 501(c)$.

${ }^{15}$ See discussion in Pizer \& Tatsutani (2008) and Newell et al. (2005).

${ }^{16}$ The economic downturn and low natural gas prices have also had a downward impact on emissions in the United States over the last few years.

${ }^{17}$ American Clean Energy and Security Act of 2009, H.R. 2454, as passed by the House of Representatives, $§ 767(c)(1)$.
} 
Differing national and regional approaches to reducing GHG emissions highlight the need to measure the comparability of policies. Among trading programs, comparability is necessary for jurisdictions to consider linking. In addition, comparability is necessary to avoid escalating concerns over competitiveness and emissions leakage that could threaten the sustainability of heterogeneous policies. The Kyoto Protocol solved this issue by having countries negotiate agreed targets for one another on the basis of a 1990 baseline. During the lead-up to the Copenhagen Accord, there was considerable debate over the adequacy and comparability of various countries' pledges. ${ }^{18}$

Most discussions of comparability look at emissions reduction efforts in one of five ways: $(a)$ emissions reductions versus a historic baseline (e.g., percent reductions compared with 1990 levels, 2005 levels), (b) emissions reductions versus a BAU baseline (e.g., percent reductions compared with projected levels in 2020), (c) reductions in emissions intensity (e.g., percent reductions per unit of gross domestic product, energy use, or power generation against a historical baseline or future projection), $(d)$ reductions in emissions per capita (also measured against a historical baseline or future projection), or $(e)$ the realized carbon price. However, there is no agreement on which metric is best. Many of these metrics raise practical issues (e.g., conversion among currencies and calculation of BAU forecasts), and different metrics yield dramatically different views.

This question of comparability is compounded when one evaluates the actual implementation of policies and their outcomes as opposed to economy-wide emissions pledges. That conversation is only just beginning as countries embark on negotiations over a new climate change agreement based on the 2011 Durban Platform for Enhanced Action and as nations grapple with domestic stakeholders that are frequently concerned about whether other major emitters, particularly their economic competitors, undertake their fair share of emissions reductions. In contrast to the situation in Kyoto, in which the dimension of comparability was a relatively narrow range of deviations from 1990 emissions levels, future comparability discussions will be much more complex. ${ }^{19}$

\subsection{International Negotiations}

What does the above discussion imply for future international negotiations concerning carbon markets? Unlike earlier negotiations that focused on top-down, larger-to-smaller emissions trading issues—national emissions caps, trading rules, and further details such as the CDM-the post-Durban negotiations will necessarily focus on the tools for a bottom-up approach. On the one hand, a new agreement will need to support concerns over comparability and transparency of effort. Those countries pursuing and already engaged in carbon markets will want assurances that other jurisdictions will do their fair share.

On the other hand, a new agreement will need to focus on ways to provide institutional support for markets themselves. Despite the various challenges that the CDM continues to face, it has an institutional structure that allows it to evolve, and it benefits significantly from its credibility derived from its role in the agreed international architecture. The negotiations could look for ways in which a wider variety of country contributions could be supported. For example, some

\footnotetext{
${ }^{18}$ See, for example, Jotzo (2010), Levin \& Bradley (2009), and Pew (2011).

${ }^{19}$ Targets under the Kyoto Protocol ranged from $8 \%$ below 1990 emissions levels for the European Union to $10 \%$ above 1990 emissions levels for Iceland (http://unfccc.int/kyoto_protocol/items/3145.php). The targets were somewhat renegotiated in the Marrakech Accords, which established limitations on the use of forestry sinks for compliance with the original targets (http://unfccc.int/methods_and_science/lulucf/items/3063.php). This relatively narrow range of targets had dramatically different consequences for countries facing different growth rates or other structural changes after 1990.
} 
developing countries might want something like model rules for establishing a domestic trading program that could link to developed country programs. Although rules for carbon markets and other abatement programs could emerge organically without an anchor in international agreements, creating model rules could be valuable, particularly for the many countries that will be too small to pursue an entirely customized approach. The CDM structure may also aid nations in developing Nationally Appropriate Mitigation Actions (NAMAs)—programs that help fund nationwide emissions reduction goals. ${ }^{20}$

There are also questions about the future of the CDM itself. Decisions in December 2012 will limit future access to the CDM to countries participating in the current phase (2013-2020) of the Kyoto Protocol. This approach steers the CDM away from a role in a decentralized global carbon market by limiting its relevance to the subset of Kyoto participants. To increase efficiency, future negotiations should be creating opportunities for linkages, not blocking them.

\section{SUMMARY}

The overarching messages from this survey are that carbon markets are sizable, they have been expanding rather than contracting, market rules are evolving and not static, and a new architecture based on a bottom-up international design raises a suite of new questions. As existing markets evolve and new trading programs emerge, market participants will take these and other developments into account.

The design of carbon markets is benefiting from experience. Experience with windfall profits from free allowance allocation has led to an increased use of auctions. Efforts to moderate high and low prices are improving efficiency and providing lessons on what works and what does not. Perhaps most importantly, we are seeing that carbon markets encourage emissions reductions, although the market signals for future investment are unclear. Arguably, the strength of those signals hinges on confidence in the emissions market, on the underlying regulatory framework and its stringency, and on the broader investment climate.

The evolving nature of carbon markets and associated design changes imply that governments cannot provide market certainty where it does not fundamentally exist. Nonetheless, market stability would benefit from authorities being clearer and more orderly about policy revisions and recognizing the consequent impacts on market price, market participants, and future market confidence.

Among the many issues facing markets in the future, the emergence of multiple emissions trading programs has highlighted the question of how, whether, and when these programs will link. A variety of motivations drive interest in linking, and we have seen a number of linking models emerge. An important question is whether links can be designed to better address various concerns ranging from harmonization and environmental integrity to the risk of a future delink.

Another issue is what role international negotiations will play regarding carbon markets in a bottom-up world. One role is to address the issue of comparability among different trading systems as well as among emissions trading, taxes, and traditional regulation. Comparability among trading systems supports linking, and comparability more generally can help avoid escalating competitiveness concerns. The latter concerns, related to both emissions and economic leakage, represent one of the greatest challenges to the long-term sustainability of carbon markets and to international climate negotiations more broadly. In addition to exploring comparability, exploring how international institutions can more directly support carbon markets in a more decentralized regime will be useful. The CDM has been a significant contribution in this regard.

${ }^{20}$ For more on NAMAs, see http://unfccc.int/focus/mitigation/items/7172.php. 
Fifteen years after the signing of the Kyoto Protocol and the creation of the first vehicle for carbon markets, the Kyoto model of a top-down, global carbon trading system is essentially over. However, carbon markets are not over. The challenge now is to determine how they can work in a much more complex-but clearly more realistic-world.

\section{DISCLOSURE STATEMENT}

The authors are not aware of any affiliations, memberships, funding, or financial holdings that might be perceived as affecting the objectivity of this review.

\section{ACKNOWLEDGMENTS}

Dallas Burtraw, Denny Ellerman, Suzi Kerr, Robert Stavins, and Jonathan Wiener provided invaluable comments on an earlier draft.

\section{LITERATURE CITED}

Aldy JE, Krupnick AJ, Newell RG, Parry IWH, Pizer WA. 2010. Designing climate mitigation policy. J. Econ. Lit. 48:903-34

Aldy JE, Pizer WA. 2009. Issues in designing US climate change policy. Energy J. 30:179-210

Anderson B, Di Maria C. 2011. Abatement and allocation in the pilot phase of the EU ETS. Environ. Resour. Econ. 48:83-103

Arrow KJ, Cropper ML, Gollier C, Groom B, Heal GM, et al. 2012. How should benefits and costs be discounted in an intergenerational context? Discuss. Pap. 12-53, Resour. Future, Washington, DC

Australia Liberal Party. 2012. Our plan to abolish the carbon tax. https://www.liberal.org.au/our-planabolish-carbon-tax

Australian Government. 2012. Australia and European Commission agree on pathway towards fully linking Emissions Trading systems. Press Release, Dep. Clim. Change Energy Effic., Aust. Gov.

Bailey E, Borenstein S, Bushnell J, Wolak F. 2012. Price containment reserve in California's greenhouse gas emissions cap-and-trade market. Issue Anal., Emissions Market Assessment Committee for AB 32 Compliance Mechanisms, Sacramento. http://www.arb.ca.gov/cc/capandtrade/emissionsmarketassessment/ pricecontainment.pdf

Barrett S. 1998. Political economy of the Kyoto Protocol. Oxf. Rev. Econ. Policy 14:20-40

Benessaiah K. 2012. Carbon and livelihoods in post-Kyoto: assessing voluntary carbon markets. Ecol. Econ. 77(May):1-6

Boden T, Marland G, Andres B. 2013. Global $\mathrm{CO}_{2}$ emissions from fossil-fuel burning, cement manufacture, and gas flaring: 1751-2010. Data Sets, Carbon Dioxide Inf. Anal. Cent., Oak Ridge Natl. Lab., Oak Ridge, Tenn. http://cdiac.esd.ornl.gov/trends/emis/meth_reg.html

Burtraw D, Evans DA. 2009. Tradable rights to emit air pollution. Aust. J. Agric. Resour. Econ. 53:59-84

Burtraw D, Palmer K, Munnings C, Weber P, Woerman M. 2013. Linking by degrees. Discuss. Pap. 13-04, Resour. Future, Washington, DC

Burtraw D, Szambelan SJ. 2009. US emissions trading markets for $\mathrm{SO}_{2}$ and $\mathrm{NO}_{x}$. Rep. 09-40, Resour. Future, Washington, DC

Calel R, Dechezleprêtre A. 2013. Environmental policy and directed technological change: evidence from the European carbon market. Work. Pap., Cent. Clim. Change Econ. Policy/Grantham Res. Inst. Clim. Change Environ., London Sch. Econ.

California Air Resources Board. 2013. Topics subject to potential regulatory amendments. http://www.arb.ca. gov/cc/capandtrade/2013summary.pdf

California Code of Regulations. 2011. California cap on greenhouse gas emissions and market-based compliance regulations. Artic. 5, Subchapter 10: Climate Change. Calif. Code Regs. tit. 17, §95800-6023 
Canadian Government. 2011. Parallel paths: Canada-US climate policy choices. Rep. 03, Natl. Roundtable Environ. Econ., Can. Gov., Ottawa

Chacko R. 2012. Outcome of Doha climate negotiations. Rep., Conserv. Int., Washington, DC. http://www. conservation.org/publications/Documents/CI_analysis_Doha_Outcomes_2012_26Nov-8Dec.pdf

Chen Y.2009. Does a regional greenhouse gas policy make sense? A case study of carbon leakage and emissions spillover. Energy Econ. 31:667-75

De Souza M. 2011. Canada won't jump into cap-and-trade carbon market on its own: Kent. Vancouver Sun, Jan. 25

Dechezleprêtre A, Glachant M, Ménière Y. 2008. The Clean Development Mechanism and the international diffusion of technologies: an empirical study. Energy Policy 36:1273-83

Demailly D, Quirion P. 2008. European Emission Trading Scheme and competitiveness: a case study on the iron and steel industry. Energy Econ. 30:2009-27

ECORYS. 2013. Carbon leakage evidence project. Fact sheet, ECORYS, Rotterdam, Neth.

Ecosystem Marketplace and Bloomberg New Energy Finance. 2008-2013. State of the voluntary carbon markets report

Ellerman DA, Convery FJ, de Perthuis C. 2010. Pricing Carbon. Cambridge, UK: Cambridge Univ. Press

Elsworth B, Worthington B. 2010. International offsets and the EU 2009: an update on the usage of compliance offsets in the EU Emissions Trading Scheme. Rep., Sandbag, London

Environmental Defense Fund and International Emissions Trading Association. 2013. Alberta: The World's Carbon Markets: A Case Study Guide to Emissions Trading. Washington, DC: Environ. Def. Fund/Int. Emiss. Trading Assoc.

Energy Information Administration. 2009. Energy Market and Economic Impacts of H.R. 2454, the American Clean Energy and Security Act of 2009. Rep., Energy Inf. Admin., Washington, DC

European Commission. 2009. EU action against climate change: the EU Emissions Trading Scheme-2009 edition. Eur. Comm., Brussels

Fallow B. 2009. Business backs emission plan changes. New Zealand Herald, Sep. 15

Fawcett AA, Calvin KV, de la Chesnaye FC, Reilly JM, Weyant JP. 2009. Overview of EMF 22 US transition scenarios. Energy Econ. 31:S198-211

Fell H, MacKenzie I, Pizer W. 2012. Prices versus quantities versus bankable quantities. Resour. Energy Econ. 34:607-23

Fell H, Morgenstern RD. 2009. Alternative approaches to cost containment in a cap-and-trade system. Discuss. Pap. 09-14, Resour. Future, Washington, DC

Fenhann J, Ipsen Hansen J, Bertule M. 2012. CDM projects. Databases, United Nations Environ. Progr., Riso Cent. http://cdmpipeline.org/

Fischer C. 2003. Combining rate-based and cap-and-trade emission policies. Clim. Policy 3(Suppl. 2):89-109

Fischer C, Fox A. 2009. Comparing policies to combat emissions leakage: border tax adjustments versus rebates. Discuss. Pap. 09-02, Resour. Future, Washington, DC

Gow D. 2006. Power tool. The Guardian, May 17. http://www.theguardian.com/environment/2006/may/ 17/europeanunion.climatechange

Hahn RW, Stavins RN. 1999. What Has the Kyoto Protocol Wrought? The Real Architecture of International Tradable Permit Markets. Washington, DC: AEI

Han G, Olsson M, Hallding K, Lunsford D. 2012. China's carbon emission trading: an overview of current development. Rep., FORES Study 2012:1, SEI/FORES, Stockholm

Harrison P. 2009. Carbon windfall profits seen for EU industry. Reuters, May 19

Ho MS, Morgenstern R, Shih J-S. 2008. Impact of carbon price policies on US industry. Discuss. Pap. 08-37, Resour. Future, Washington, DC

Interagency Competitiveness Analysis Team. 2009. The effects of H.R. 2454 on international competitiveness and emission leakage in energy-intensive trade-exposed industries. Rep., EPA, Washington, DC

Interagency Working Group on Social Cost of Carbon (Interagency). 2009. Social cost of carbon for regulatory impact analysis under Executive Order 12866. Tech. Supp. Doc., Interagency, US Gov., Washington, DC

Interagency. 2013. Technical update of the social cost of carbon for regulatory impact analysis under Executive Order 12866. Tech. Supp. Doc., Interagency, US Gov., Washington, DC 
Jaffe AB, Newell RG, Stavins RN. 2002. Environmental policy and technological change. Environ. Resour. Econ. 22:41-69

Jaffe J, Ranson M, Stavins RN. 2009. Linking tradable permit systems: a key element of emerging international climate policy architecture. Ecol. Law Q. 36:789-808

Jotzo F. 2010. Comparing the Copenhagen emission targets. Res. Rep. 1078, Environ. Econ. Res. Hub, Crawford Sch. Public Policy, Aust. Natl. Univ., Canberra

Kindle AG, Shawhan DL, Swider MJ. 2011. An empirical test for inter-state carbon-dioxide emissions leakage resulting from the Regional Greenhouse Gas Initiative. Present., Rensselaer Polytech. Inst./N. Y. Indep. Syst. Oper.

Kruger J, Oates WE, Pizer WA. 2007. Decentralization in the EU Emissions Trading Scheme and lessons for global policy. Rev. Environ. Econ. Policy 1:112-33

Lacombe RH. 2008. Economic impact of the European Union Emission Trading Scheme: evidence from the refining sector. PhD Thesis, Mass. Inst. Technol., Cambridge, Mass.

Lambert RS. 2011. Perverse incentives under the CDM: an evaluation of HFC-23 destruction projects. Clim. Policy 11:851-64

Lecocq F, Ambrosi P. 2007. The Clean Development Mechanism: history, status, and prospects. Rev. Environ. Econ. Policy 1:134-51

Leiter AM, Paolini A, Winner H. 2011. Environmental regulation and investment: evidence from European industry data. Ecol. Econ. 70:759-70

Levin K, Bradley R. 2009. Comparability of Annex I emission reduction pledges. Work. Pap., World Resour. Inst., Washington, DC

Mace MJ, Millar I, Schwarte C, Anderson J, Broekhoff D, et al. 2008. Analysis of the legal and organizational issues arising in linking the EU Emission Trading Scheme to other existing and emerging emission trading schemes. Rep., World Resour. Inst., Washington, DC

Mehling M, Haites E. 2011. Mechanisms for linking emissions trading schemes. Clim. Policy 9:169-84

Murray BC, Newell RG, Pizer WA. 2009. Balancing cost and emissions certainty: an allowance reserve for cap-and-trade. Rev. Environ. Econ. Policy 3:84-103

National Research Council. 2010. Climate change: overview of quantifying and valuing climate-change impacts. In Hidden Costs of Energy: Unpriced Consequences of Energy Production and Use, pp. 248-506. Washington, DC: Natl. Acad. Press

Neuhoff K, Schopp A, Boyd R, Stelmakh K, Vasa A. 2012. Banking of surplus emissions allowances: Does the volume matter? Work. Pap. 1196, DIW, Berlin

New Zealand Government. 2012. The New Zealand Emissions Trading Scheme. https://www.climatechange. govt.nz/emissions-trading-scheme/

Newell RG. 2010. The role of markets and policies in delivering innovation for climate change mitigation. Oxf. Rev. Econ. Policy 26:253-69

Newell RG, Pizer WA. 2003. Regulating stock externalities under uncertainty. J. Environ. Econ. Manag. 45:416-32

Newell RG, Pizer WA, Raimi D. 2014. Carbon market lessons and global policy outlook. Science 343:1316-17

Newell RG, Pizer WA, Zhang J. 2005. Managing permit markets to stabilize prices. Environ. Resour. Econ. 31:133-57

Olsen KH. 2007. The Clean Development Mechanism's contribution to sustainable development: a review of the literature. Clim. Change 84:59-73

Pew Center on Global Climate Change (Pew). 2011. Common metrics: comparing countries' climate pledges. Policy Brief, Pew, Washington, DC

Pizer WA. 2002. Combining price and quantity controls to mitigate global climate change. J. Public Econ. 85:409-34

Pizer WA, Tatsutani M. 2008. Managing costs in a US greenhouse gas trading program. Discuss. Pap. 08-23, Resour. Future, Washington, DC

Pizer WA, Yates AJ. 2013. Breaking up may not be hard to do: terminating links between emission trading programs. Rep. RPP-2013-12, Regul. Policy Progr., Harvard Kennedy Sch. 
Popp D. 2011. International technology transfer, climate change, and the Clean Development Mechanism. Rev. Environ. Econ. Policy 5:131-52

Reinaud J. 2008. Climate policy and carbon leakage: impacts of the European Emissions Trading Scheme on aluminium. Inf. Pap., Int. Energy Agency, Vienna

Reklev S. 2012. Australia to link with $\mathrm{EU} \mathrm{CO}_{2}$ market, drops price floor. Point Carbon, Aug. 27. https://www. pointcarbon.com/news/1.1967394

Reklev S. 2013. Factbox: China's seven pilot $\mathrm{CO}_{2}$ trading markets. Point Carbon, June 17. https://www. pointcarbon.com/news/1.2422941? \& ref=searchlist

Sandel M. 1997. It's immoral to buy the right to pollute. N. Y. Times, Dec. 15

Schroeder M. 2009. Utilizing the Clean Development Mechanism for the deployment of renewable energies in China. Appl. Energy 86:75-90

Sijm J, Hers S, Lise W, Wetzelaer B. 2008. The impact of the EU ETS on electricity prices. Final Rep. to DG Environ. Eur. Comm., Brussels

Stanway D. 2013. China climate chief says $\mathrm{EU} \mathrm{CO}_{2}$ crisis will not hurt domestic plans. Reuters, Apr. 18

Stavins RN. 1998. What can we learn from the grand policy experiment? Lessons from $\mathrm{SO}_{2}$ allowance trading. J. Econ. Perspect. 12:69-88

Sutter C, Parreno JC. 2007. Does the Current Clean Development Mechanism deliver its sustainable development claim? An analysis of officially registered CDM projects. Clim. Change 84:75-90

Szabo M. 2013. EU carbon vols down 23 pct y/y in Oct amid shift to bourses. Point Carbon, Nov. 1. http:// www.pointcarbon.com/news $/ 1.2725173$

Tarr J, Monast J, Profeta T. 2013. Regulating carbon dioxide under Section 111(d) of the Clean Air Act: options, limits, and impacts. Rep., Nicholas Inst. Environ. Policy Solut., Duke Univ., Durham, N. C.

Tietenberg TH. 1985. Emissions Trading. Washington, DC: Resour. Future

Tuerk A, Mehling M, Flachsland C, Sterk W. 2009. Linking carbon markets: concepts, case studies, and pathways. Clim. Policy 9:341-57

United Nations Framework Convention on Climate Change (UNFCCC). 2012. Global warming potentials. https://unfccc.int/ghg_data/items/3825.php

Wara M. 2008. Measuring the Clean Development Mechanism's performance and potential. UCLA Law Rev. 55:1759-803

Weitzman ML. 1974. Prices vs. quantities. Rev. Econ. Stud. 41:477-91

Weyant JP, Hill J. 1999. Introduction and overview. In Costs of the Kyoto Protocol: a Multi-Model Evaluation [Energy Journal Special Issue], ed. JP Weyant, pp. vii-xliv. Cleveland, OH: Int. Assoc. Energy Econ.

Wiener J. 2001. Something borrowed for something blue: legal transplants and the evolution of global environmental law. Ecol. Law Q. 27:1295-371

Wing IS, Kolodziej M. 2009. The Regional Greenhouse Gas Initiative: emission leakage and the effectiveness of interstate border adjustments. Work. Pap., Dep. Geogr. Environ., Boston Univ.

World Bank. 2013. Carbon markets of the future are forming where you might not expect. News Artic., World Bank, Washington, DC

Zhang J, Wang C. 2011. Co-benefits and additionality of the Clean Development Mechanism: an empirical analysis. J. Environ. Econ. Manag. 62:140-54 


\section{Autobiographical}

A Conversation with Irma Adelman

Irma Adelman, David Zilberman, and Eunice Kim ............ 1

\section{Resources}

Measuring the Wealth of Nations Partha Dasgupta ................................ 17

Optimal Control in Space and Time and the Management of Environmental Resources

W.A. Brock, A. Xepapadeas, and A.N. Yannacopoulos ........... 33

Natural Resources and Violent Conflict Eleonora Nillesen and Erwin Bulte . . . . . . . . . . . . . . . . . . 69

Regime Shifts in Resource Management Aart de Zeenw ............................... 85

Fiscal Rules and the Management of Natural Resource Revenues:

The Case of Chile Luis Felipe Céspedes, Eric Parrado, and Andrés Velasco ............ 105

\section{Energy}

Oil Price Shocks: Causes and Consequences Lutz Kilian . . . . . . . . . . . . . . . . . . . . . . . . . . . . . 133

The Economics of Energy Security Gilbert E. Metcalf ............................ 155

Auctioning Resource Rights

Kenneth Hendricks and Robert H. Porter . . . . . . . . . . . . . 175 
Carbon Markets: Past, Present, and Future

Richard G. Newell, William A. Pizer, and Daniel Raimi

\section{Environment}

What Do We Know About Short- and Long-Term Effects of Early-Life Exposure to Pollution?

Janet Currie, Joshua Graff Zivin, Jamie Mullins, and Matthew Neidell . . 217

Valuing Morbidity in Environmental Benefit-Cost Analysis

Trudy Ann Cameron ... . . . . . . . . . . . . . . . . . . . 249

The Long-Run Discount Rate Controversy

Christian Gollier and James K. Hammitt . . . . . . . . . . . . . . . . . 273

Consumption- Versus Production-Based Emission Policies

Michael Jakob, Jan Christoph Steckel, and Ottmar Edenhofer . . . . . . . 297

Economic Experiments and Environmental Policy

Charles N. Noussair and Daan P. van Soest . . . . . . . . . . . . . . . . . 319

The Economics of Environmental Monitoring and Enforcement

Jay P. Shimshack . . . . . . . . . . . . . . . . . . . . 339

Payment for Ecosystem Services from Forests

Jennifer Alix-Garcia and Hendrik Wolff . . . . . . . . . . . . . . . 361

Agriculture

Consumer Acceptance of New Food Technologies: Causes and Roots of Controversies

Jayson L. Lusk, Jutta Roosen, and Andrea Bieberstein . . . . . . . . . . . . 381

The Economics of Voluntary Versus Mandatory Labels

Brian E. Roe, Mario F. Teisl, and Corin R. Deans . . . . . . . . . . . . . 407

Limitations of Certification and Supply Chain Standards for Environmental Protection in Commodity Crop Production

Kurt B. Waldman and John M. Kerr . . . . . . . . . . . . . . . . . . 429

Theory and Application of Positive Mathematical Programming in

Agriculture and the Environment

Pierre Mérel and Richard Howitt

\section{Development}

Agriculture in African Development: Theories and Strategies

Stefan Dercon and Douglas Gollin . . . . . . . . . . . . . . . . . 471 
Trade Liberalization and Poverty: What Have We Learned in a Decade?

L. Alan Winters and Antonio Martuscelli ................... 493

The Intersection of Trade Policy, Price Volatility, and Food Security

Kym Anderson ................................ 513

The Power of Information: The ICT Revolution in Agricultural Development

Eduardo Nakasone, Maximo Torero, and Bart Minten . . . . . . . . . 533

\section{Errata}

An online log of corrections to Annual Review of Resource Economics articles may be found at http://www.annualreviews.org/errata/resource 